\title{
FDAMA Section 114: Why the Renewed Interest?
}

\author{
Eleanor M. Perfetto, PhD, MS; Laurie Burke, RPh, MPH; \\ Elisabeth M. Oehrlein, BA; and Mena Gaballah, BS
}

\section{SUMMARY}

The FDA regulates the use of information by biopharmaceutical companies in their promotional activities. Section 114 of the Food and Drug Administration Modernization Act of 1997 (FDAMA) was specifically designed to allow companies to more readily disseminate health care economic information (HCEI) to those who need it for formulary decision making. However, very little HCEI has been distributed promotionally under this provision over the past 17 years. There are recent discussions by stakeholders regarding the need for updates, revisions, or guidance regarding Section 114.

In light of recent renewed interest in Section 114 of the FDAMA, the purpose of this commentary is to equip managed care decision makers with the information they need to understand and respond to industry communications that are governed by Section 114. This commentary reviews and synthesizes the regulatory history and language of the statute and changes to the promotion regulation generated by Section 114. It explores the reasons for the section's limited use to date, for recent renewed interest, and why changes by various stakeholders are suggested at this time. Also discussed is what managed care pharmacists need to know about Section 114, and suggestions are included regarding the active role pharmacists can play in this change process.

Renewed interest in FDAMA Section 114 appears to stem largely from the increasingly visible and growing interest in comparative effectiveness research, the emergence of "big data," the expanding range of data sources available for deriving $\mathrm{HCEl}$, and recent court decisions that might indicate a change in the regulatory environment. Various stakeholders are proposing recommendations regarding changes to FDAMA Section 114. Managed care pharmacists should be aware that companies are restricted when communicating HCEI promotional messages; this may mean seeing the use of FDAMA Section 114 as the "competent and reliable" effectiveness standard in promotion. If the managed care pharmacy community communicates clearly about what information it needs and the format in which it wants to receive that information, companies, policymakers, and regulatory bodies can work collaboratively with managed care pharmacy to create a regulatory environment that supports transparent communication of desired information.

J Manag Care Spec Pharm. 2015;21(5):368-74

Copyright $\odot 2015$, Academy of Managed Care Pharmacy. All rights reserved.

\section{What is already known about this subject}

There is a growing need for managed care pharmacists to have access to reliable health care economic information (HCEI) for decision making.

While Section 114 of the Food and Drug Administration Modernization Act of 1997 (FDAMA) was passed to support the provision of HCEI to formulary decision makers, its use and impact have been questioned by many stakeholders.

\section{What this study adds}

This review provides managed care pharmacy decision makers with foundational information for understanding FDAMA Section 114 , the renewed interest in it, and the proposed legislative and policy changes in discussion.

This review provides suggestions for managed care pharmacy regarding its leadership role in advocating for a process that meets its needs-one that provides access to the information decision makers want in the format they prefer-while ensuring appropriate regulatory oversight to prevent communication of false and misleading information, and at the same time not being a barrier to information access

$\mathrm{F}$ or well over 20 years, health care economic information (HCEI), such as cost-effectiveness, has been in demand by managed care organizations and other payers, such as pharmacy benefit managers, to aid in drug formulary decisions. The U.S. Congress recognized that "health economic information about approved 'on-label' uses is needed by managed care experts and other healthcare providers responsible for evaluating the benefits, other consequences, and costs of competing therapies." Further, Congress also recognized that biopharmaceutical "companies typically have the best and most comprehensive information about the cost, effectiveness, and safety of their products." Section 114 of the Food and Drug Administration Modernization Act of 1997 (FDAMA) amended the Federal Food, Drug, and Cosmetic Act (FFDCA) to significantly modify the standard for U.S. Food and Drug Administration (FDA) regulation of HCEI communicated by a biopharmaceutical company to a formulary committee or similar entity. ${ }^{2}$ Section 114 was intended to enable the sharing of useful HCEI sought by decision makers.

In the 17 years since Section 114 of the FDAMA was passed, managed care organizations, pharmacy benefit managers, and other health insurers making decisions on the behalf of beneficiaries are still seeking the same types of HCEI. The passage of the Affordable Care Act and its formation of the PatientCentered Outcomes Research Institute (PCORI), with its focus on comparative effectiveness research (CER), have spurred renewed discussions about FDAMA Section 114.

The purpose of this commentary is to equip managed care pharmacists with the information they need to understand FDAMA Section 114 and the proposed potential changes to the statute suggested by various stakeholders. The statute and why it was an important change to FDA regulation are outlined. Also discussed are the reasons for the renewed interest in Section 


\section{FIGURE 1 Evolution of Drug Effectiveness Evidence and Communication Standards}

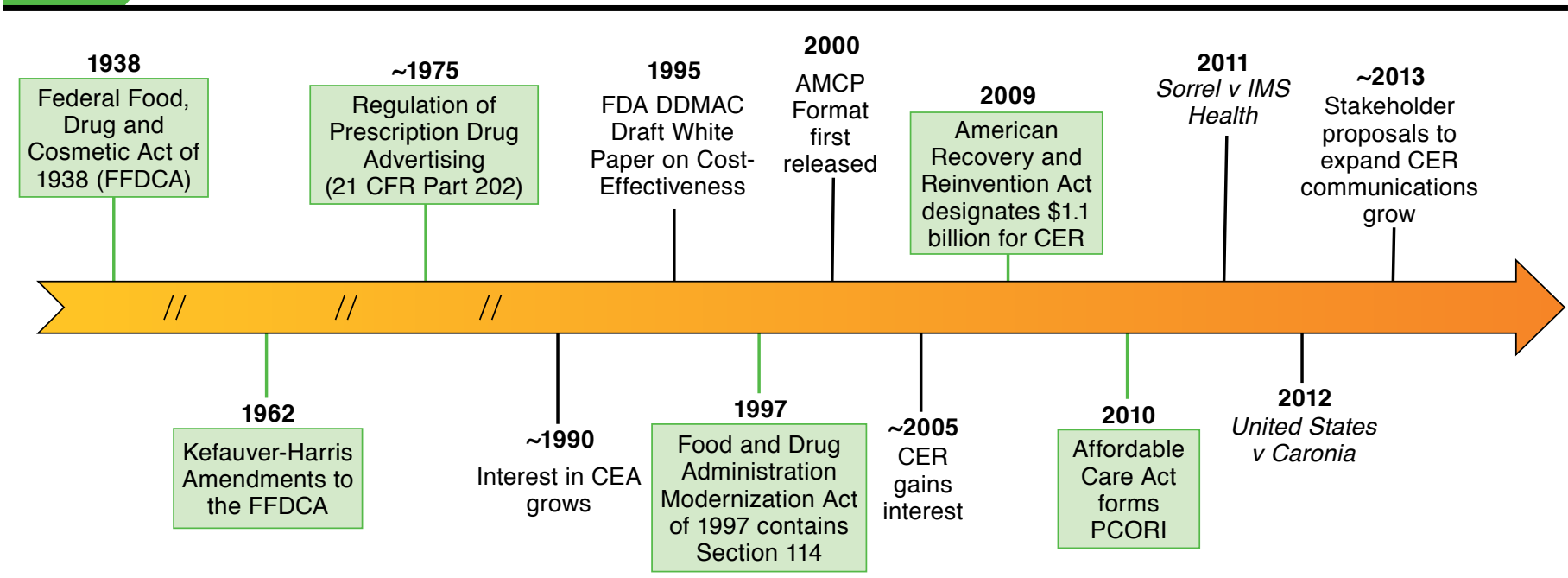

Note: Boxed events denote governmental action.

AMCP = Academy of Managed Care Pharmacy; CEA = cost-effectiveness analysis; CER=comparative effectiveness research; CFR=Code of Federal Regulations;

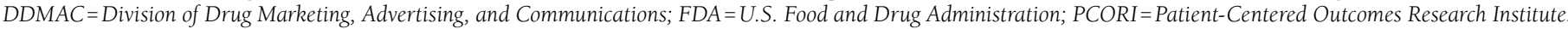

114 , the reasons for suggested updates, and suggestions regarding the role of managed care pharmacy in acquisition of HCEI.

\section{History of FDA Regulation of}

\section{Communication of Economic Information}

Federal regulation of drug labeling was authorized in 1906, and the FDA began regulating the manufacture, promotion, and sale of drugs in 1938 with the FFDCA (see timeline depicted in Figure 1). Under section 502(a) of the FFDCA, a drug is deemed to be misbranded "if its labeling is false or misleading in any particular." ${ }^{3,4}$ In general, prescription drug labeling misbrands a drug product if it is false, lacking in fair balance, or otherwise misleading., ${ }^{5,6}$

The 1962 Kefauver-Harris Drug Amendments to the FFDCA added the requirement that drug makers need to prove that their drugs are efficacious before the FDA can approve them for sale. These 1962 amendments established "substantial evidence" as the standard for efficacy to support claims in labeling or promotion. Substantial evidence means "evidence consisting of adequate and well-controlled investigations." The FDA generally interprets this requirement to mean that a company must provide evidence from at least 2 adequate and well-controlled clinical studies to support an efficacy claim in promotion. ${ }^{6}$ The 1962 amendments also gave the FDA jurisdiction over prescription drug promotion, with oversight of whether the benefits and risks of treatment are presented in a truthful, nonmisleading, fair, and balanced manner.

FDA regulations define 2 types of prescription drug promotion: advertising and promotional labeling. Advertisements include promotional material that appears in print periodicals such as journals, magazines, and newspapers, as well as broadcast media such as television, radio, and telephone systems. ${ }^{7}$ While FDA-required labeling is generally approved by the FDA before distribution with the product, promotional labeling is not reviewed by the FDA before it is distributed and is defined as any written, printed, or graphic matter that bears a "textual relationship" with a drug or device. ${ }^{3}$ Therefore, although a pamphlet sent to a physician's office may not carry a "physical attachment" to the specific drug, it is still considered to be promotional labeling due to a textual relationship with the drug. ${ }^{8}$

\section{Section 114 of the FDAMA}

Although FDA oversight of advertisements and promotional labeling began in 1962, Congress did not anticipate the structural changes in the health care system between 1962 and the early 1990s that would drive the use of HCEI as a relevant topic in prescription drug promotion..$^{9,10}$ Because of the proliferation of new treatment options, skyrocketing costs, and uncertainty over which treatments are most effective, payers were seeking to contain costs while making the best choices for their beneficiaries. ${ }^{11}$ In response, companies wanted to be able to make claims based on their analyses. As an indicator of the growing interest in HCEI, the quantity of publications identified under the search term cost-effectiveness analysis increased dramatically between 1990 and 2012 (see Figure 2). ${ }^{12}$

FDA staff were dedicated to prescription drug promotion review and enforcement in the 1980s, and the Division of Drug Marketing, Advertising and Communications (DDMAC) was established in the early 1990s. ${ }^{13,14}$ In 1995, DDMAC drafted a white paper on cost-effectiveness (also referred to as a DDMAC unreleased draft guidance) in response to the proliferation of 


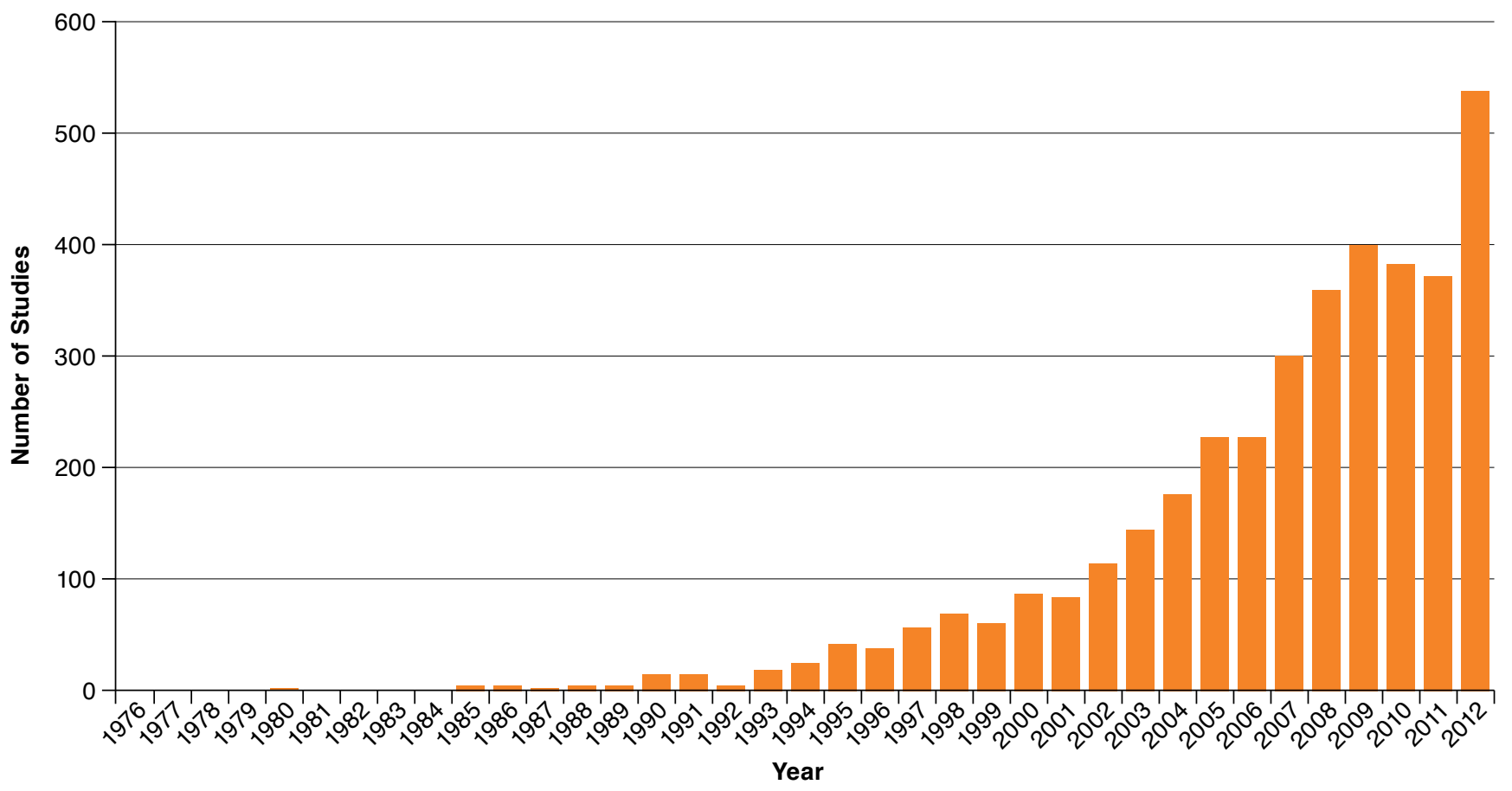

CEA = cost-effectiveness analysis.

CEA studies and dissemination by the pharmaceutical industry. The FDAMA was passed in 1997 to specifically address the use of HCEI in prescription drug promotion to managed care. ${ }^{15}$ Section 114 of the FDAMA amended the FFDCA provisions regarding misbranded drugs or devices by adding an existing Federal Trade Commission evidence standard-"competent and reliable scientific evidence" - to the FDA's authorization in section 502(a). ${ }^{2}$ (See specific language in Figure 3.)

Section 114 mandates the application of the "competent and reliable scientific evidence" standard to FDA review of HCEI in prescription drug promotion if it is "provided to a formulary committee, or other similar entity" and "directly relates" to an approved indication. ${ }^{2}$ By changing the standard of evidence for the dissemination of HCEI to experts who make health plan coverage decisions, Congress sought to increase the flow of that information by removing undue restrictions on companies. Congress was convinced that these undue restrictions "interfere with the public health because of the sale and use of needlessly expensive products." However, Section 114 did not change the substantial evidence requirement that applies to effectiveness claims in all other types of prescription drug labeling and promotion.

Section 114 is limited in scope. For example, it does not address regulatory standards related to industry-supported scientific and educational activities and manufacturer responses to unsolicited requests for information about a drug. ${ }^{16}$ Section

\section{FIGURE 3 Food and Drug Administration} Modernization Act: Section 114 Language $^{2}$

(a) In General.-Section 502(a) (21 U.S.C. 35152(a)) is amended by adding at the end the following: "Health care economic information provided to a formulary committee, or other similar entity, in the course of the committee or the entity carrying out its responsibilities for the selection of drugs for managed care or other similar organizations, shall not be considered to be false or misleading under this paragraph if the health care economic information directly relates to an indication approved under section 505 or under section 351(a) of the Public Health Service Act for such drug and is based on competent and reliable scientific evidence. The requirements set forth in section 505(a) or in section 351(a) of the Public Health Service Act shall not apply to health care economic information provided to such a committee or entity in accordance with this paragraph. Information that is relevant to the substantiation of the health care economic information presented pursuant to this paragraph shall be made available to the Secretary upon request. In this paragraph, the term 'health care economic information' means any analysis that identifies, measures, or compares the economic consequences, including the costs of the represented health outcomes, of the use of a drug to the use of another drug, to another health care intervention, or to no intervention."

114 also does not affect the FDA's current guidance on the dissemination of medical journal articles and scientific or medical reference publications that discuss unapproved new uses for approved drugs or approved or cleared medical devices 


\section{TABLE 1 Specific Terms Used in Food and Drug Administration Modernization Act Section 114}

\begin{tabular}{|c|c|c|}
\hline Term & Definition & Caveats \\
\hline Health care economic information & $\begin{array}{l}\text { "Any analysis that identifies, measures, or compares the economic } \\
\text { consequences, including the costs of the represented health outcomes, } \\
\text { of the use of a drug to the use of another drug, to another health care } \\
\text { intervention, or to no intervention." }\end{array}$ & $\begin{array}{l}\text { Appears to exclude comparisons based } \\
\text { solely on effectiveness or efficacy }\end{array}$ \\
\hline $\begin{array}{l}\text { Formulary committee or other } \\
\text { similar entity }\end{array}$ & $\begin{array}{l}\text { "Committee or the entity carrying out its responsibilities for the selec- } \\
\text { tion of drugs for managed care or other similar organizations"3 }\end{array}$ & $\begin{array}{l}\text { Appears to exclude communications with } \\
\text { individual practitioners }\end{array}$ \\
\hline $\begin{array}{l}\text { Competent and reliable scientific } \\
\text { evidence }\end{array}$ & $\begin{array}{l}\text { "Tests, analysis, research, studies or other evidence based on the } \\
\text { expertise of professionals in the relevant area...conducted and evalu- } \\
\text { ated in an objective manner by persons qualified to do so, using } \\
\text { procedures generally accepted by others in the profession to yield } \\
\text { accurate and reliable results." } 39\end{array}$ & $\begin{array}{l}\text { Appears to require substantiation but does } \\
\text { not necessarily require clinical trial data }\end{array}$ \\
\hline $\begin{array}{l}\text { Directly relates to an approved } \\
\text { indication }\end{array}$ & Refers to an FDA-approved use for the product. & $\begin{array}{l}\text { Appears to forbid any extension beyond an } \\
\text { FDA-approved label use }\end{array}$ \\
\hline
\end{tabular}

FDA =U.S. Food and Drug Administration.

marketed in the United States to health care professionals and health care entities. ${ }^{17}$

Section 114 changed the evidence standard for industry communication of economics-related promotional information. At no other time since the 1962 drug amendments established the substantial evidence standard has an alternate standard of evidence been adopted by the FDA for the regulation of prescription drug products. However, the limitations of this provision, as will be discussed, impeded the flow of information that was contemplated by Congress in enacting FDAMA Section 114.

In line with the intent of Congress to increase the flow of economic information, and despite the prescription drug industry's increased efforts to generate that evidence, the Academy of Managed Care Pharmacy (AMCP) first released the AMCP Format for Formulary Submissions in 2000. The AMCP Format provides managed care organizations (MCOs) with comprehensive drug information (dossiers) directly from the company but minimizes legal quandaries. ${ }^{18}$ The AMCP Format circumvents Section 114 because it relates only to unsolicited requests from a health care system to a pharmaceutical manufacturer. Unlike information distributed under Section 114, this activity is not considered promotional. ${ }^{19}$ Following a learning curve on the part of MCOs and drug companies, the AMCP Format gained traction, leading to the loss of prominence for FDAMA Section 114.20,21

Recently, a renewed effort to define standards for what constitutes competent and reliable scientific information has generated interest among the pharmaceutical industry, health care decision makers, and regulators in order to make informative HCEI more available. ${ }^{22}$

\section{Why So Little Use of FDAMA Section 114?}

While the intent of Section 114 was to improve the flow of HCEI to those who need it for decision making, it is clear that goal has not been achieved. Neumann reported in 2009 that there appeared to be too little discussion, use, or general interest in Section 114 over the 10 years after its enactment. ${ }^{21}$ Reasons for the lack of use were hypothesized as murky rules, restrictiveness, and the use of the AMCP Format. ${ }^{15}$
To some extent, the interpretation of Section 114 has been unclear. For example, questions remain over who specifically is the intended audience for competent and reliable scientific information? Does the recipient of the information need to be a Pharmacy and Therapeutics Committee member? Or, can any pharmacist employed by an MCO receive this information? These ambiguous aspects of Section 114 also include determination of what information is directly related to the required product labeling. It may seem that this is straightforward, as the labeled indication. However, MCOs clearly are looking for information that goes beyond the labeled indication. These potentially ambiguous terms are listed in Table 1.

As a result of this ambiguity, companies may hesitate to share HCEI broadly because they are not sure who can legally receive this information. For example, comparative effectiveness information is critical to MCOs but is rarely included in drug labeling. However, without a specific economic analysis, a strict interpretation of Section 114 would not allow the new evidence standard to be applied to that information in promotion. A company would be prohibited from including the information in promotional materials if the comparative effectiveness information does not meet the traditional substantial evidence standard.

In addition, questions that remain pertaining to the interpretation of Section 114 may in large part go unaddressed because of the widespread use of the AMCP Format. Companies have invested substantially in the development of these extensive dossiers guided by the AMCP Format to meet the demands of these unsolicited requests for information. ${ }^{14}$

\section{Why the Renewed Interest in FDAMA Section 114?}

In the last several years, there has been renewed interest in Section 114 due to several factors: (a) more visible emphasis on comparative value as evidenced by recent U.S. legislation that includes funding of CER; (b) "big data" and an ever-expanding range of sources of input for deriving HCEI; and (c) recent court decisions that might indicate a change in the regulatory environment and an increased appetite for regulatory challenges. Each of these is discussed in the following sections. 


\section{Emphasis on Comparative Value}

Comparative value is at the forefront of health care policy because of the resource-constrained and economically stressed environment in which the United States finds itself. Both the 2009 American Reinvestment and Recovery Act (ARRA) and the 2010 Affordable Care Act (ACA) included CER provisions. ${ }^{23-25}$ The ARRA legislation dedicated $\$ 1.1$ billion to funding CER over a 2-year period. ${ }^{26}$ In 2010, the ACA was signed into law by President Barack Obama with a provision to establish PCORI, committing an estimated $\$ 6$ billion to CER over a 10 -year period. ${ }^{27}$ This public-private effort will substantially increase the amount of CER information generated and disseminated. While PCORI technically is not a government entity, its origin in the ACA legislation, and the substantial government investments in it, provides its findings with implied governmental imprimatur. Increased CER will likely result in more comparative findings being communicated by all parties. In keeping with this trend, drug companies may endeavor to use FDAMA Section 114 as an avenue to disseminate CER findings. It remains to be seen how much CER results in HCEI and when comparative drug information is considered to be directly related to the labeled indications in the eyes of the regulators.

\section{Growing Importance of "Big Data"}

As part of the ARRA and the ACA, investment in health care informatics was also prominent. Many private and public organizations are investing in what is being referred to as "big data." ${ }^{28}$ Multipayer and industry consortia collaborating, merging, and acquiring data, infrastructure, technologies, and expertise translates into not only more CER data resources, but also a variety of methods for CER generation and dissemination..$^{29,30}$ Since these databases will likely be used for observational studies and modeling, companies could benefit from finding a way to disseminate these findings under the purview of Section 114 when communicating results.

\section{Legal Challenges to FDA Regulation of Speech}

Finally, over the last few years, there have been several successful legal challenges pertaining to FDA regulation of communication or commercial speech, including United States v Caronia and Sorrell $v$ IMS Health.

In the Caronia case, a pharmaceutical sales representative was convicted of off-label promotion of a prescription drug. The Second Circuit Court overturned Caronia's conviction on the grounds that it impermissibly criminalized protected speech and violated his First Amendment freedom of speech rights. In this case, the court stated that "the government cannot prosecute pharmaceutical manufacturers and their representatives under the FDCA for speech promoting the lawful, off-label use of an FDA-approved drug as long as that speech was not false or misleading. ${ }^{31}$

The Sorrell v IMS Health case was in response to passage of the Prescription Confidentiality Act. This act "prohibits the sale, license, or exchange for value of personal information data for the purpose of selling or marketing a prescription drug." ${ }^{32}$ The question was whether or not the state of Vermont could impose a restriction on industry use of data when that restriction is not imposed upon any other user of that data. The U.S. Supreme Court decided in favor of IMS Health, stating that a "State cannot engage in content-based discrimination to advance its own side of a debate." ${ }^{33}$ The state of Vermont was attempting to prevent pharmaceutical companies from using records that reveal the prescribing practices of providers. Again, the court stated that the Vermont statute that imposed the restriction was a violation of the First Amendment.

These 2 cases are examples of recent activity in the courts that may be a signal of an environmental shift. If companies were being cautious in the past for fear of possible legal recriminations, these recent legal findings could be a sign of, or an encouragement for, more aggressive actions, especially in light of rulings that favor commercial free speech.

\section{Implications for Managed Care Pharmacy}

Pharmacists need to be aware that companies communicating their HCEI promotional messages may use the Section 114 "competent and reliable" effectiveness standard. Table 2 provides a review of specific points from Section 114 that are relevant to managed care formulary committees. When HCEI is reviewed by a clinician, a concomitant review of approved prescribing information is recommended to understand the original basis of product approval and to help put the HCEI in context. However, when a decision maker believes he or she has inadequate information to support prescribing or formulary decisions, a request for additional specific information from the drug company is an option. A request based on use of the AMCP Format is a way to approach a company with an unsolicited request for information. But, more specific questions can be posed, and a company can respond fully without legal restriction. ${ }^{34}$

Methodology standards and criteria for decision makers to use when assessing the available CER data are under development by organizations such as the CER Collaborative, of which the AMCP is a member ${ }^{35-37}$ This type of effort supports managed care pharmacists in sorting through the relevance and credibility of the information communicated to them in published studies and through promotional vehicles.

Regulators, legislators, and national health policymakers have recognized the need for more accessible information to support formulary and other medical decision making. They acknowledge the need for more research with improved availability and communication of study findings in practical terms that are useful to decision makers. In addition, the implementation of CER under the ARRA and the ACA will clearly generate new data and much scrutiny. It could generate new ideas for future legislative proposals on the communication of CER information. However, only if additional drug company promotional activities in the area of CER and/or HCEI come to the attention of the FDA, would additional guidance be expected to address regulatory policy in these areas.

It has been rumored for several years that the FDA will release guidance on Section 114. Recently, the FDA announced that draft guidance would not be released at this time, although it is in development. ${ }^{38}$ Rather than wait for additional FDA 


\section{TABLE 2 Key Take-Away Points}

for Decision Makers

What do Formulary Committee Members

Need to Know about FDAMA Section 114?

- Applies to a specific type of data: health care economic information. It does not apply to all clinical information.

- Applies to a specific audience: formulary committees or other similar entities responsible for making drug selections for managed care or other similar organizations. It is not intended that it be used to communicate with the public, patient, or individual providers.

- Enables a company to provide health care economic information to a formulary committee. This is information that may be forbidden by the FDA from being provided to individuals or other groups under the Public Health Service statutes regarding company promotion.

- Applies only to health care economic information, not comparative effectiveness claims with no economic components. While the foundation for an economic claim may be based on a comparative clinical assessment, the comparative clinical assessment cannot be the sole basis for the communication under Section 114.

- Applies to health care economic information that is related to an approved FDA indication for a drug.

FDA =U.S. Food and Drug Administration; FDAMA = Food and Drug

Administration Modernization Act.

guidance on these issues to create a pathway for accessing information, managed care pharmacy may take a more active role, as it did in developing the AMCP Format. Managed care pharmacy can clearly articulate the types of information it needs (e.g., HCEI, CER, and patient-reported outcomes research); the format it prefers; and preferred vehicles for communication. This can help the FDA understand the environment in which the communication takes place, as well as the requested content (e.g., desired endpoints). It can also help companies in assessing appropriate vehicles for information dissemination. As the predominate stakeholder in the process, and to support access to appropriate and necessary information, managed care pharmacy should take a lead role in clearing the pathway for communication by shedding light on issues that Section 114 of the FDAMA was never intended to address and cannot resolve.

\section{Conclusions}

Managed care pharmacists should be aware that companies are restricted when communicating HCEI promotional messages. For this reason, FDAMA Section 114 was originally intended to ease the provision of HCEI to formulary decision makers. A number of stakeholders believe this was not fully achieved and that FDA guidance is warranted or that the statute needs to be updated or replaced. Thus, Section 114 is undergoing renewed scrutiny and discussion.

Since formulary decision makers were the intended recipients of Section 114, managed care pharmacy has the opportunity to step into a leadership role, advocating for a process that suits its needs and a process that provides access to the information decision makers want in the format they prefer. If the managed care pharmacy community articulates clearly what information it needs and how it wants to receive that informa- tion, then companies, policymakers, and regulatory bodies can work collaboratively with managed care pharmacy to create a regulatory environment that supports transparent communication of the desired information. This kind of collaboration may produce a process that ensures both appropriate regulatory oversight to prevent communication of false and misleading information, and one that is not a barrier to information.

\section{Authors}

ELEANOR M. PERFETTO, PhD, MS, is Professor; ELISABETH M. OEHRLEIN, BA, is a Graduate Student; and MENA GABALLAH, $B S$, is a PharmD Student, Department of Pharmaceutical Health Services Research, University of Maryland School of Pharmacy, Baltimore. LAURIE BURKE, RPh, MPH, is Affiliate Associate Professor, Department of Pharmaceutical Health Services Research, University of Maryland School of Pharmacy, Baltimore, and Founder, LORA Group, Royal Oak, Maryland.

AUTHOR CORRESPONDENCE: Elisabeth M. Oehrlein, BA, Dept. of Pharmaceutical Health Services Research, University of Maryland School of Pharmacy, 220 Arch St., 12th Fl., Baltimore, MD 21201. Tel.: 410.706.0908; Fax: 410.706.5394; E-mail: eoehrlein@umaryland.edu.

\section{DISCLOSURES}

None of the authors have received funding for the development of this research or manuscript. Perfetto has received research funding from the CER Collaborative, the National Pharmaceutical Council, and PhRMA Foundation and is a consultant to pharmaceutical companies. Burke is also a consultant to pharmaceutical companies.

Study concept was contributed primarily by Perfetto and Burke. Data collection, analysis, and manuscript revision were performed by Perfetto, Burke, and Oehrlein. The manuscript was written primarily by Perfetto and Burke, along with Oehrlein and Gaballah.

\section{REFERENCES}

1. U.S. Senate. Committe on Labor and Human Resources. Food and Drug Administration Modernization and Accountability Act of 1997. Report 10543. Available at: http://www.gpo.gov/fdsys/pkg/CRPT-105srpt43/pdf/CRPT105srpt43.pdf. Accessed April 12, 2015.

2. U.S. Food and Drug Administration. Food and Drug Administration Modernization Act (FDAMA) of 1997. November 21, 1997. Available at: http://www.fda.gov/regulatoryinformation/legislation/federalfooddrugandcosmeticactfdcact/significantamendmentstothefdcact/fdama/default.htm. Accessed April 14, 2015.

3. Misbranded Drugs and Devices. 21 U.S.C. Section 352(a). United States Code, 2010 edition. U.S. Government Publishing Office. Available at: http:// www.gpo.gov/fdsys/pkg/USCODE-2010-title21/html/USCODE-2010-title21chap9-subchapV-partA-sec352.htm. Accessed April 12, 2015.

4. Internal Committee for Review of Pediatric Plans, Assessments, Deferrals, and Waivers. 21 U.S.C. Section 355(d). United States Code, 2010 edition. U.S. Government Publishing Office. Available at: http://www.gpo.gov/fdsys/ pkg/USCODE-2010-title21/html/USCODE-2010-title21-chap9-subchapVpartA-sec355d.htm. Accessed April 12, 2015

5. U.S. Food and Drug Administration. Kefauver-Harris amendments revolutionized drug development. October 10, 2012. Available at: http://www.fda.gov/ ForConsumers/ConsumerUpdates/ucm322856.htm. Accessed April 12, 2015. 
6. Adequate and well-controlled studies. 21 CFR Chapter 1, section 314.126. 2010 edition. U.S. Government Publishing Office. Available at: http:// www.gpo.gov/fdsys/pkg/CFR-2010-title21-vol5/pdf/CFR-2010-title21-vol5sec314-126.pdf. Accessed April 12, 2015.

7. U.S. Food and Drug Administration. Drug advertising: a glossary of terms. Available at: http://www.fda.gov/Drugs/ResourcesForYou/Consumers/ PrescriptionDrugAdvertising/ucm072025.htm. Accessed April 12, 2015.

8. U.S. Supreme Court. Kordel v United States. 335 U.S. 345 (1948). Available at: http://supreme.justia.com/cases/federal/us/335/345/case.html. Accessed April 12, 2015.

9. Feldstein PJ. The changing structure of the health care delivery system in the United States. J Med Pract Manage. 1985;1(1):13-19.

10. Moses H, Matheson DH, Dorsey ER, George BP, Sadoff D, Yoshimura S. The anatomy of health care in the United States. JAMA. 2013;310(18):1947-63.

11. Luke RT. Health care in the United States: current and future challenges. Manag Care. 2001;10(10 Suppl):2-6.

12. Cost-Effectiveness Analysis Registry. What is the CEA Registry? Tufts Medical Center. Available at: https://research.tufts-nemc.org/cear4/AboutUs/ WhatistheCEARegistry.aspx. Accessed April 12, 2015.

13. Kessler DA, Pines WL. The federal regulation of prescription drug advertising and promotion. JAMA. 1990;264(18):2409-15.

14. Vodra WW, Cortez NG, Korn DE. The Food and Drug Administration's evolving regulation of press releases: limits and challenges. Food Drug Law J. 2006;61(4):623-51.

15. U.S. House. Committee on Commerce. Prescription Drug User Fee Reauthorization and Drug Regulatory Modernization Act of 1997. H.R. 105-310, pp. 65-66. U.S. Government Publishing Office. Available at: http:// www.gpo.gov/fdsys/pkg/CRPT-105hrpt310/pdf/CRPT-105hrpt310.pdf. Accessed April 12, 2015.

16. U.S. Department of Health and Human Services. Final guidance on industry-supported scientific and educational activities. 62 Federal Register 64074, December 3, 1997. Available at: http://www.gpo.gov/fdsys/pkg/ FR-1997-12-03/pdf/97-31741.pdf. Accessed April 12, 2015.

17. U.S. Food and Drug Administration. Guidance for industry. Good reprint practices for the distribution of medical journal articles and medical or scientific reference publications on unapproved new uses of approved drugs and approved or cleared medical devices. January 2009. Available at: http://www.fda.gov/regulatoryinformation/guidances/ucm125126.htm. Accessed April 12, 2015.

18. Nichol MB, Knight TK, Epstein J, Honda DH, Tretiak R. Opinions regarding the Academy of Managed Care Pharmacy dossier submission guidelines: results of a small survey of managed care organizations and pharmaceutical manufacturers. J Manag Care Pharm. 2007;13(4):360-71. Available at: http://www.amcp.org/data/jmcp/360-71.pdf.

19. Academy of Managed Care Pharmacy. AMCP Format for Formulary Submissions, Version 3.1. January 2013. Available at: http://www.amcp.org/ practice-resources/amcp-format-formulary-submisions/.

20. Cross M. Formulary submission process catches on ... slowly. Manag Care. 2002;11(11):32-36. Available at: http://www.managedcaremag.com/ archives/0211/0211.amcp_update.html. Accessed April 12, 2015.

21. Neumann PJ. What ever happened to FDAMA Section 114? A look back after 10 years. Value Health. 2009;12(2):189-90. Available at: http://onlinelibrary. wiley.com/doi/10.1111/j.1524-4733.2008.00429.x/pdf. Accessed April 12, 2015. 22. Perfetto EM, Bailey JE Jr, Gans-Brangs KR, Romano SJ, Rosenthal NR, Willke RJ. Communication about results of comparative effectiveness studies: a pharmaceutical industry view. Health Aff (Millwood). 2012;31(10):2213-19. 23. Neumann PJ. Health economics communication and FDAMA Section 114. Presented at: Chicago ISPOR Chapter; May 2, 2013; Chicago, IL. Available at: http://www.ispor.org/regional_chapters/chicago/documents/ neumann-ispor-chicago-2013-05-02-v2_final.pdf. Accessed April 14, 2015. 24. American Recovery and Reinvestment Act of 2009. 105th Congress, 1st session. H.R. 1. January 6, 2009. U.S. Government Publishing Office. Available at: http://www.gpo.gov/fdsys/pkg/BILLS-11lhrlenr/pdf/BILLS11lhrlenr.pdf. Accessed April 12, 2015.
25. Patient Protection and Affordable Care Act. 11lth Congress, 2nd session. H.R. 3590. January 5, 2010. U.S. Government Publishing Office. Available at: http://www.gpo.gov/fdsys/pkg/BILLS-11lhr3590enr/pdf/BILLS11lhr3590enr.pdf. Accessed April 12, 2015.

26. Agency for Healthcare Research and Quality. Overview of the American Recovery and Reinvestment Act of 2009. Available at: http://archive.ahrq. gov/funding/arra/overview/index.html. Accessed April 15, 2015.

27. Perfetto EM. Industry response to CER expectations. Presented at: XL Pharma CER Evidence Summit: Counteracting the Impact of Generating Comparative Effectiveness Research Winners and Losers; April 2012; Washington, DC.

28. Cattell J, Sastry C, Levy M. How big data can revolutionize pharmaceutical R\&D. McKinsey \& Company. April 2013. Available at: http://www.mckinsey.com/insights/health_systems_and_services how_big_data_can_revolutionize_pharmaceutical_r_and_d. Accessed April 12, 2015.

29. Chappel A. Multi-Payer claims database (MPCD) for comparative effectiveness research. National Committee on Vital and Health Statistics. Full Committee Meeting. June 2011. Available at: http://www.ncvhs.hhs.gov/wpcontent/uploads/2014/05/110616pl.pdf. Accessed April 12, 2015.

30. Terry K. Optum, Mayo join forces to exploit big data. InformationWeek. January 16, 2013. Available at: http://www.informationweek.com/healthcare/ clinical-information-systems/optum-mayo-join-forces-to-exploit-big-data/d/ d-id/1108233?. Accessed April 12, 2015.

31. U.S. Court of Appeals for the Second Circuit. United States of America $v$ Alfred Caronia. Docket No. 09-5006-cr. 2012; pp. 20, 25-26, 31. Available at: http://www.hpm.com/pdf/blog/Caronia\%202d\%20Circuit\%20Slip\%20 Opinion.pdf. Accessed April 12, 2015.

32. DeWeese N, Rumpf J. Sorrell v IMS Health, Inc. (10-779). Legal Information Institute Supreme Court Bulletin. 2011. Available at: https:// www.law.cornell.edu/supct/cert/10-779. Accessed April 12, 2015.

33. U.S. Supreme Court. Sorrell, Attorney General of Vermont, et al. v IMS Health Inc. et al. No. 10-779. 2010; p. 24. Available at: http://www.supremecourt.gov/opinions/10pdf/10-779.pdf. Accessed April 12, 2015.

34. U.S. Food and Drug Administration. Guidance for industry. Responding to unsolicited requests for off-label information about prescription drugs and medical devices. Draft guidance. December 2011. Available at: http://www. fda.gov/downloads/Drugs/GuidanceComplianceRegulatoryInformation/ Guidances/UCM285145.pdf. Accessed April 12, 2015.

35. Berger M, Martin B, Husereau D, et al, A questionnaire to assess the relevance and credibility of observational studies to inform healthcare decision making: an ISPOR-AMCP-NPC good practice task force report. Value Health. 2014;17(2):143-56.

36. Jaime Caro J, Eddy DM, Kan H, et al. Questionnaire to assess relevance and credibility of modeling studies for informing health care decision making: an ISPOR-AMCP-NPC Good Practice Task Force report. Value Health. 17(2):174-82.

37. Jansen JP, Trikalinos T, Cappelleri JC, et al. Indirect treatment comparison/network meta-analysis study questionnaire to assess relevance and credibility to inform health care decision making: an ISPOR-AMCP-NPC Good Practice Task Force report. Value Health. 2014;17(2):157-73.

38. Sutter, S. FDA guidance on health care economic data is coming in 2015 "The Pink Sheet" Daily. January 2, 2015. Available at: https://www.pharmamedtechbi.com/publications/the-pink-sheet-daily/2015/1/2/fda-guidanceon-health-care-economic-data-is-coming-in-2015. Accessed April 12, 2015. 39. Fair L. Substantiation: the science of compliance. Bureau of Consumer Protection Business Center, Federal Trade Commission. March 6, 2012. Available at: http://cdn3.assets.sites.launchrocketship.com/b417d565-99de46ec-b27c-22f2b0f5cddc/files/44d48lcd-afc7-4cf2-b3d2-240c054953fl/ substantiation__the_science_of_compliance___bcp_business_center.pdf. Accessed April 12, 2015. 